\title{
Open thoracoabdominal aneurysm repair in octogenarians: Is the enemy of good, perfect?
}

\author{
Leonard N. Girardi, MD
}

\section{See related article on pages S134-41.}

Open thoracoabdominal aortic aneurysm (TAAA) repair remains a formidable surgical undertaking. Despite major advances in operative technique, anesthesia, and perioperative care, the risk of respiratory failure, renal failure, stroke, and paraplegia remain challenges that have yet to be overcome. Even in experienced centers with a team dedicated to caring for the patient with an aneurysm, the incidence of end-organ failure is increased when we extend the indications for surgery into very-high-risk cohorts. In a previous era, octogenarians with extensive TAAAs would have been considered inappropriate candidates for extensive repairs. However, as our experience with the elderly has grown in other areas of cardiovascular surgery, ${ }^{1}$ it is a natural progression to explore the limits of our intraoperative and postoperative skills in a much more complicated procedure such as TAAA repair. In this issue of the Journal of Thoracic and Cardiovascular Surgery, Aftab and colleagues ${ }^{2}$ build on a previous publication ${ }^{3}$ of the senior author's experience with TAAA repair in octogenarians. The results in this more contemporary compendium are worthy of discussion as the risk in certain extremely high-risk subgroups may dissuade even the most experienced centers and surgeons away from the operating theatre in favor of a much less aggressive approach.

Although one would certainly expect an increase in risk for octogenarians undergoing TAAA repair, the staggering incidence of significant postoperative complications is sobering. In-hospital mortality was nearly quadruple that seen in younger populations ( $26 \%$ vs $6.9 \%)$. Major adverse events were significantly more common (36\% vs $15.3 \%)$ with permanent spinal cord deficits occurring more than twice as often as that seen in a previous report. ${ }^{4}$ Renal failure was a particularly vexing problem with an incidence of $23 \%$ despite the use of renoprotective strategies such as left heart bypass and cold renal perfusion. The addition of renal

From the Department of Cardiothoracic Surgery, Weill Cornell Medical College, New York, NY

Disclosures: Author has nothing to disclose with regard to commercial support.

Received for publication Sept 22, 2014; accepted for publication Sept 27, 2014; available ahead of print Oct 22, 2014.

Address for reprints: Leonard N. Girardi, MD, Department of Cardiothoracic Surgery, Weill Medical College of Cornell University, 525 East 68th St, M-424, New York, NY 10021 (E-mail: lngirard@med.cornell.edu).

J Thorac Cardiovasc Surg 2015;149:S142-3

$0022-5223 / \$ 36.00$

Copyright (C) 2015 by The American Association for Thoracic Surgery

http://dx.doi.org/10.1016/j.jtcvs.2014.09.111 artery stenting or endarterectomy in more than $50 \%$ of the patients did disappointingly little to reduce the 4-fold increase in the need for dialysis after surgery. Not unexpectedly, the more extensive the aneurysm, the worse the patients did. Patients in need of repair of an extent II aneurysm, total aortic replacement from the left subclavian artery to the aortic bifurcation, had an in-hospital mortality rate of $62 \%$ (odds ratio, 11.6). Their incidence of postoperative renal failure was nearly $70 \%$ and major pulmonary complications were seen in $77 \%$ of those having this most extensive aneurysm repair. Although survival was only calculated out to 1 year, there was a nearly $20 \%$ reduction in actuarial survival when comparing the octogenarians with a younger group undergoing TAAA repair. The authors concluded that although this therapy should not be withheld from octogenarians, one should proceed with caution when considering such an extensive procedure in the elderly.

These results should give one great pause before proceeding with open TAAA repair in patients more than 80 years of age. Despite the most extensive experience in TAAA repair in the world, ${ }^{4}$ these experienced surgeons were unable to overcome the significant increase in risk even in those undergoing elective repair. Thirty-two percent of the 88 octogenarians examined in this study required urgent or emergency intervention for rupture, acute dissection, or other acute aortic syndromes. In these instances, death is imminent and it seems reasonable to offer intervention to a select group with few alternatives. However, when comparing the outcomes in those with extent I and II aneurysms undergoing elective repair, one is left wondering if a nonoperative approach might be preferable. The natural history of aneurysm rupture, dissection, or aneurysm-related death is approximately $15.6 \%$ per year in aneurysms of $6 \mathrm{~cm}$ or more in diameter. ${ }^{5}$ Might one be better counseled to take this 1 in 7 risk of death stratified over a year rather than the $32 \%$ to $62 \%$ in-hospital mortality seen in the best of hands for the most extensive types of TAAAs?

One last logical question generated by these data is what is the role of thoracic endovascular aneurysm repair (TEVAR)? TEVAR was shown to be effective in octogenarians with isolated descending aneurysms with an in-hospital mortality of $10 \% .{ }^{6}$ However, none of these patients had aneurysms extending below the diaphragm. Endovascular reconstruction of the renal and visceral vessels was not performed. Intermediate-term results using fenestrated stent grafts are equivalent at best and there is a dearth of data with this intricate procedure in more extensive extent I 
and II aneurysms. ${ }^{7}$ Time will tell if this is a viable alternative in those of advanced age.

Open repair remains the gold standard therapy for patients with TAAA. A continued reduction in mortality and permanent life-altering complications allows us to offer this complicated procedure to an increasingly highrisk cohort of patients. The data from this study are vital in helping to identify appropriate elderly patients who will avoid fatal aneurysm rupture and experience improved survival with a quality of life after surgery that is similar to an age-matched population. However, for those with more complicated and extensive aneurysms, or significant comorbid conditions, extreme caution should be exercised. Even in the most experienced hands, the outcomes for these patients are marginal and arguably worse than tempting fate with medical therapy alone. TEVAR may further expand the pool of octogenarians eligible for repair of their TAAA. However, we have yet to see the full spectrum of problems associated with endovascular therapy and, in the end, may all agree that the best therapy for some TAAAs is leaving well enough alone rather than pursuing perfection.

\section{References}

1. Krane M, Voss B, Hiebinger A, Deutsch MA, Wottke M, Hapfelmeier A, et al Twenty years of cardiac surgery in patients aged 80 years and older: risks and benefits. Ann Thorac Surg. 2011;91:506-13.

2. Aftab M, Songdechakraiwut T, Green SY, Zarda S, Price MD, Nalty CC, et al Contemporary outcomes of open thoracoabdominal aortic aneurysm repair in octogenarians. J Thorac Cardiovasc Surg. 2015;149:S134-41.

3. Girardi LN, Coselli JS. Repair of thoracoabdominal aortic aneurysms in octogenarians. Ann Thorac Surg. 1998;65:491-5.

4. Coselli JS, Bozinovski J, LeMaire SA. Open surgical repair of 2286 thoracoabdominal aortic aneurysms. Ann Thorac Surg. 2007;83:S862-4; discussion S90-2.

5. Davies RR, Goldstein LJ, Coady MA, Tittle SL, Rizzo JA, Kopf GS, et al. Yearly rupture or dissection rates for thoracic aortic aneurysms: simple prediction based on size. Ann Thorac Surg. 2002;73:17-28.

6. Preventza O, Bavaria J, Ramaiah V, Moser GW, Szeto W, Wheatley G, et al Thoracic endografting is a viable option for the octogenarian. Ann Thorac Surg. 2010;90:78-82.

7. Greenberg R, Eagleton M, Mastracci T. Branched endografts for thoracoabdominal aneurysms. J Thorac Cardiovasc Surg. 2010;140:S171-8. 